\title{
Approach for the development of a method for the integration of battery electric vehicles in commercial companies, including intelligent management systems
}

\author{
Johannes Betz ${ }^{1} \cdot$ Markus Lienkamp ${ }^{1}$
}

Received: 2 December 2015 / Accepted: 28 July 2016/Published online: 3 August 2016

(C) Springer International Publishing Switzerland 2016

\begin{abstract}
Current analyses of electric mobility reveal that the electrification of the powertrain of vehicles will change the entire automotive value chain. This paper presents the approach for the development of a method for the evaluation of an economically and ecologically rewarding integration of electric vehicles in commercial companies. First, this method focuses on the analysis of the driving behavior of a commercial vehicle fleet and the energy flow (consumption and production) in a company. Second, it is the goal to evaluate the potential of integrating battery electric vehicles in a commercial company using a new developed fleet-management system in combination with an energy- and chargingmanagement system. The potential of integration will be depicted by the number of battery electric vehicles that can be integrated, the reduction of the total costs of ownership, and the reduction of the produced $\mathrm{CO}_{2}$ emissions.
\end{abstract}

Keywords Battery electric vehicle $\cdot$ Commercial · Optimization · Charge management · Energy management . Fleet management

\section{Introduction and motivation}

Results of the current research programs, for example, the BMWi sponsored "Information and communication technology (ICT) for Electric Mobility II" [1], show: There is a

Johannes Betz

betz@ftm.mw.tum.de

$\triangle$ Markus Lienkamp

lienkamp@ftm.mw.tum.de

1 Institute of Automotive Technology, Technical University of Munich, Garching at Munich, Germany potential for the electrification of the powertrain in the vehicle segment of light trucks, buses, and transport vehicles, which also includes the service and delivery fleets of companies. This particular category of service and delivery vehicles represents driving profiles and mobility pattern systematics that indicate a high potential for the electrification of the powertrain [2]. In addition, the use of commercial vehicles is always well planned and calculated. In addition, the vehicles return to the premises of the company at the end of the day again [3]. In contrast to a private vehicle, the advantage of using a battery electric vehicle (BEV) in companies is that the vehicles only have to distinguish a range between 100 and $200 \mathrm{~km} \mathrm{[1,4].} \mathrm{As} \mathrm{of}$ today, there are still some unresolved issues.

First, there is no analysis that examines commercial companies for the potential of reducing total costs of ownership (TCO) and $\mathrm{CO}_{2}$ emissions by integrating BEVs in combination with a fleet-, energy-, and charging-management system.

Second, the current market availability of vehicle concepts for electric mobility is strongly limited, although the need for specially configured vehicles for defined business areas will continue to increase. Therefore, it is unclear which electric vehicle concepts ought to be used prospectively in companies. There is no method which evaluates the BEV concept regarding battery capacity, electrical drivetrain, or maximum charging power for the application in commercial companies.

Third, there are no holistic business models for an economic operation of a company involving the connection of BEVs and a fleet-, energy-, or charging-management system. Today, there is no method which evaluates the overall potential of including BEVs with one of these systems in a commercial company.

These disadvantages lead to the objective of developing a method which provides the overall potential of 
integrating $\mathrm{BEVs}$ in commercial companies by using management systems. The goal of the authors' research is to use this method for analyzing every commercial company which wants to be consulted by the integration of electric vehicles. The approach for this method is shown in Fig. 1.

In the first step, an actual state analysis of the company is made with a new developed simulative analyzing tool. In the actual state analysis, the company has to provide the number of current vehicles, the current fleet test data from selected vehicles, the current energy consumption (power and energy flow), and the current usage of different energy producers.

In the second step, using the real data from the company, an evaluation of the potential of integrating BEVs is made. In this optimization, a new developed tool evaluates the cost and emission reduction potential for the company using BEVs. This optimization is made by simulating a consistently substitution of current internal combustion engine vehicles in the company with BEVs. In addition, this optimization integrates the combination of the described fleet-, energy-, and charging-management systems. After the simulation, the following questions can be answered:

- How many BEVs can the individual company integrate in their fleet without getting any mobility behavior issues?

- Which BEV concepts can be integrated in the company: e.g., Drivetrain topology, battery capacity?

- Is it useful to integrate the BEV stupid or is one of the management systems necessary?

- Which TCO advantages do the BEV integration has for the company?

- Which $\mathrm{CO}_{2}$ advantages do the BEV integration has for the company?

After that, it is possible to constitute recommendations for actions for the individual company and integrate the described BEV concepts and management systems from the optimization. On the one hand, it has to be considered which vehicle concepts, in regard to the battery capacity and powertrain topology, are most suitable. On the other hand, the companies consist of energy producers (e.g., renewable energies) and energy consumers which have to be combined with the existing charging infrastructure. This new holistic method combines, analyzes, and optimizes both energy and vehicle fleet for the commercial company.
In prior research, there are no studies which are surveying the optimization potential in a company by integrating a fleet of BEVs and different management systems. In addition, no research program deals with the aim to develop a simulative analyzing tool for commercial companies by integrating BEVs and an energy-, fleet-, or charging management.

\section{Related work}

The idea of integrating electric vehicles in the commercial sector is investigated by different authors. Aichinger follows the question if it is useful to integrate electric vehicles in the inner city logistics [5]. In [6, 7], different surveys are examined to display the needs of the commercial vehicle users. Gnann et al. [8] provide an overall market potential analysis for the usage of BEVs in the German commercial passenger transport sector.

For the proposed approach in this paper, the authors are using mobility data which is collected in the field operational test of "Virtual Electromobility Munich" [9]. The method of collecting, managing, and processing data (communications with the servers) which is applied in this field operational test can be used for the data analyzing approach in this paper. Cauwer et al. identificated BEV use patterns on the basis of BEV monitoring data [10]. Corcherco et al. analyzed electric vehicle fleets in different European cities. Additional conventional vehicle and BEV analysis were made in [11-13].

The idea of this paper is the smart combination of a BEV fleet with an energy-, charging-, or fleet-management system. This means that the vehicles are integrated in an intelligent way in the commercial company. This intelligent integration is surveyed in many papers and research projects for the usage in the private household and is known as "Smart Home" [14-17]. The intelligent integration of BEVs in the commercial sector is a field with a high new value and is only displayed in few papers. For example, Maasman displays the usage of renewable energies in smart factories with electric vehicle fleets [18]. Valero-Bover et al. [19] analyzing the performance of and electric vehicle fleet for the commercial purpose, and Taefi et al. [20] are displaying a framework to enhance the productivity of electric commercial vehicles. None of them is building a holistic simulation model which evaluates the cost and emission benefits by

Fig. 1 Method for the integration of BEVs in companies

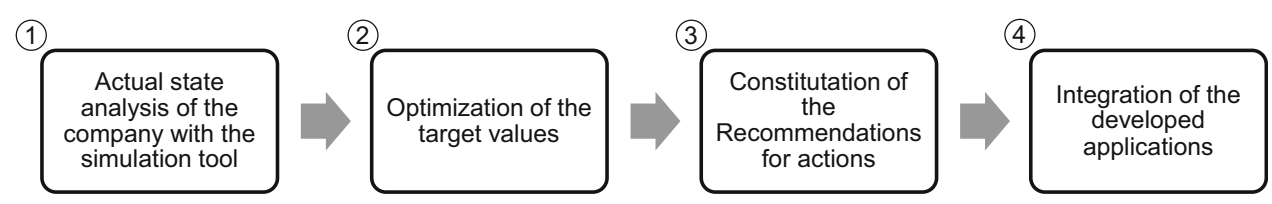


integrating a BEV fleet witch different management systems in a commercial company.

When talking about cost and emission benefits, Samweber et al. [21] survey the question, whether and to what extend the self-consumption of self-produced energy can be increased using an electric vehicle and/or a stationary battery system. Quaschning et al. presenting the chances of using photovoltaic (PV) produced energy for the self-consumption [22]. Hacker et al. [1] presenting a TCO model for the usage of electric vehicles in commercial usage, and Kahlen et al. [23] displaying a profitable business model for electric fleet owners.

The project "IRENE" [24] deals with the integration of renewable energy and electric vehicles in existing energy networks. The focus is to control the prospective generated energy from renewable energy sources (PV, wind energy, hydroelectric, and biogas systems). The research is about the general investigation of the network status and does not consider the self-sufficient energy management of a commercial enterprise in combination with the vehicle fleet. In "lokSMART" [25], the use of local combined heat and power (CHP) plants and renewable sources in combination with electrical buffers and electric vehicles is investigated. In this project, the general use and market potential are elaborated, and a renewably-powered charging station with bidirectional quick charge function is developed.

Nowadays, there are different approaches to control vehicle fleets. The project "Shared e-Fleet" [26] presents the development of a cloud-based solution for car sharing of electric vehicles in small and medium companies. Sassi and Oulamara describing a joint scheduling and optimal charging problem for electric vehicles [27]. Another possible solution for an E-Mobility Fleet Management is described in [28], where an ant algorithm is used for the fleet-management system.

To sum up, there is many literature which analysis and examines different questions for the integration of BEVs or the increment of self-produced energy. There is no research project or paper which examines the combination of different management systems to evaluate the cost and emission potential for the integration of BEVs in commercial companies.

\section{Method development}

Numerous scientific studies investigate the cost and emission optimization potential through the integration of BEVs in a household. Brendle [15] summarizes that the objectives of such an integration are usually the smoothing of the electrical load profile, cost reduction, emission reduction, or the development of an autarkic system.
The approach in this paper surveys the possibility to increase different target values in commercial companies by integrating BEVs. Specifically, for commercial companies, the following target values can be optimized, although it should be noted that these are partially incoherent and partially contrary targets:

- Life cycle assessment: reduction of the $\mathrm{CO}_{2}$ emissions.

- Enlarge self-sufficiency: usage of self-produced energy.

- Balance the energy grid load: storage of electrical power.

- Improve profitability of the company: TCO reduction.

- Increase the utilization of the fleet capacity: usage of more BEVs.

For the development of the method for evaluating the BEV integration in different companies in Fig. 1, we propose a multi-tiered approach as a research concept, which is illustrated in Fig. 2.

This approach is based on the division of the whole method development in a virtual and real experiment. The virtual experiment consists of the analysis of the collected data and the development of the simulation systems. The real experiment consists of a real application of the individual management systems and different BEVs in a selected company to collect data for the evaluation of the systems and the method.

In the first step of the virtual experiment, various company data have to be analyzed to gain knowledge of the particularities at different commercial companies. First, the mobility behavior of different commercial companies has to be analyzed. The authors are using movement profiles with speed, altitude, and GPS information of 35 vehicles which belong to different commercial companies and have already been collected in the VEM project [9]. Such an analysis is necessary, because then a representative statement about the driving behavior of the vehicles from the company is conceivable. This analysis includes in total the average travel time periods, average standing time, arrival and departure times, and an overview of the covered distances. In addition, it is possible to simulate every trip with a longitudinal dynamic model to gain knowledge of the diverse energy consumption of the vehicles. In addition, some of these companies have smart metering systems which collect data of the energy usage in the company. The energy and power floss is recorded for different energy producers (e.g., a PV system) and energy consumers (e.g., overall load of the company). With this information, it can be evaluated if it is possible to combine the energy producers and the electric vehicles.

In the second step, the collected data from vehicle data loggers and smart metering systems in selected companies are used to develop a simulation tool for analyzing the individual company. This simulation tool includes the 
Fig. 2 Overall concept of the method development: virtual and real experiment

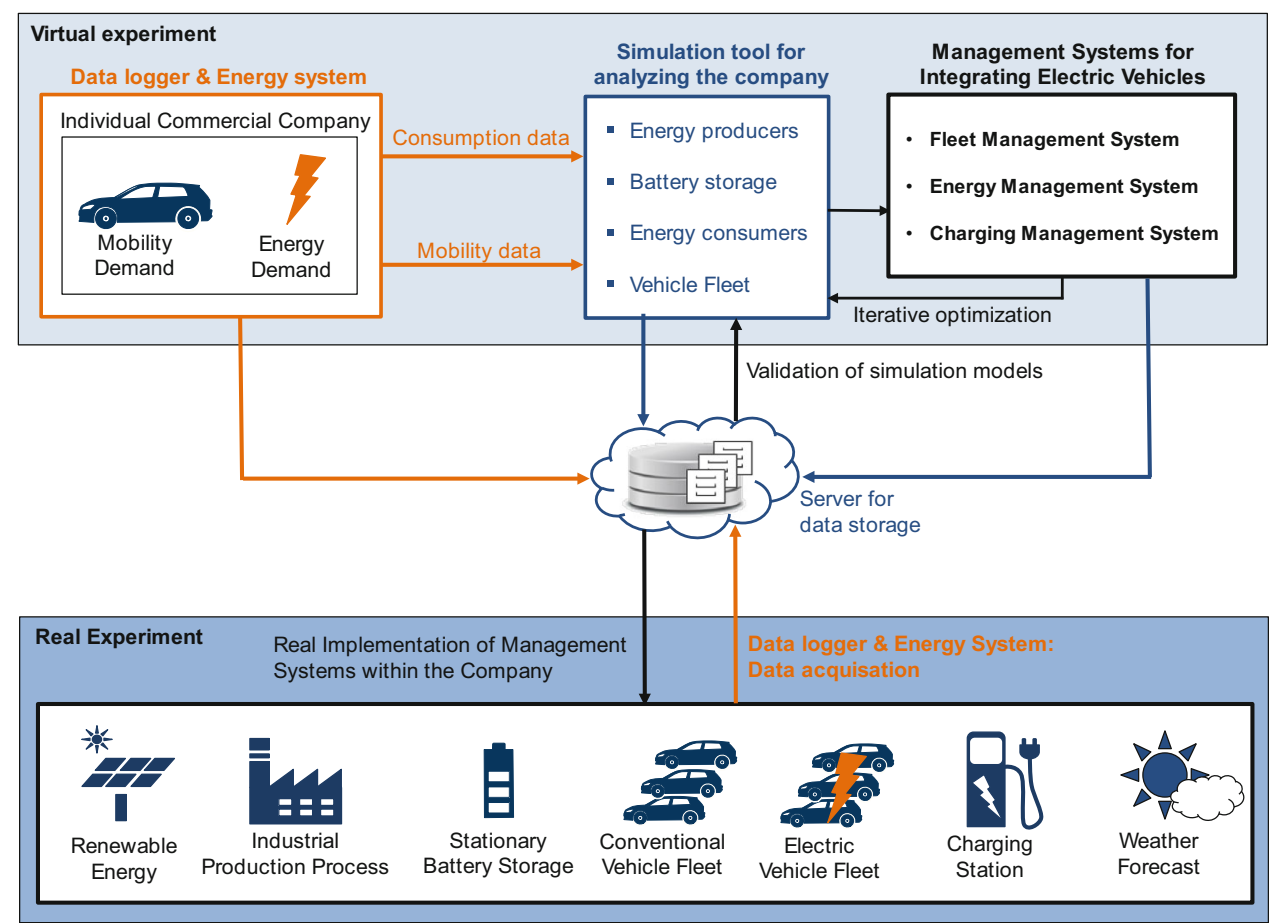

energy producers (e.g., PV systems) as well as the energy consumers that are represented by the electric vehicle fleet or an industrial manufacturing process (energy load) in the company. Depending on the application, different electrical energy storage devices can be included in the simulation model. The objective of the tool is to produce a holistic simulation model of every possible combination of vehicle and energy systems in the company. In addition, it is possible to evaluate the influences of the various systems to each other. With the knowledge of the interferences in the overall system, different applications can be developed to optimize the entire system from an economic (reduce of $\mathrm{CO}_{2}$ emissions) and ecological (reduce of TCO) point of view.

The third step of the virtual experiment includes the development of three management systems which can either integrated alone or in combination in the company to gain more advantages in the cost and emission reduction:

- Fleet management: one of the major goals is the development of a fleet-management or fleet-disposition system for the integration of BEVs in a commercial company. With this management system, it is possible to customize a predictive fleet planning for BEVs for increasing the fleet utilization rate. In addition, the charging stations at the company location can be utilized in an optimal way.

- Energy management: an energy management system enables the optimal utilize of the available energy from the different resources in conjunction with the vehicle fleet. Furthermore, with the integration of an electrical energy storage, it is possible to store cheap and $\mathrm{CO}_{2}$ free produced energy for the later usage. The control of the energy flow leads to an increase of the selfconsumption rate, the increase of the self-sufficiency level, and a decrease in the $\mathrm{CO}_{2}$ emissions.

- Charging management: with the development of a smart distribution software, it is feasible to build a smart network between the charging stations and the vehicles in the company. By knowing every parameter of the $\mathrm{BEV}$, it is possible to control the loading time of both fleet vehicles and vehicles of the employees depending on peak loads, electricity prices, and time. In combination with the fleet-management system, the energy self-sufficient level can increase as well as the self-consumption rate.

In addition to these management systems, with the illustrated analysis method, it is feasible to derive individual and new electric vehicle concepts for companies. These vehicle concepts differ in the size of the battery, the drivetrain topology, the overall vehicle concept (e.g., transporter, light commercial vehicle, etc.), and specific vehicle parameters (e.g., weight, aerodynamic parameters, etc). Therefore, it is conceivable, to evaluate existing electric vehicle concepts for commercial companies.

The virtual experiment will be accompanied by a real experiment with real vehicles and real energy producers and consumers in selected commercial companies. In different test scenarios, all company owned vehicles are equipped with GPS data loggers which record the mobility behavior and transmit the recorded data to the backend 
while driving. In addition, existing energy systems in the selected companies store the real-time data of energy producers and consumer on the backend. The developed simulation models can be validated and optimized. In addition, in this real experiment, the fleet-, energy-, and charging management can be implemented with the corresponding hardware in the company. These systems can now be operate regarding ecological or economical optimization with the developed optimization algorithms. The results of the usage of these systems in combination with the BEVs will be stored on the backend and are used to optimize these management systems and algorithms.

\section{Virtual experiment}

The entire investigation in the overall research concept starts with conducting of the virtual experiment. The advantage of a virtual experiment is that all developed concepts, methods, and approaches can be examined virtually in an affordable way. With the usage of selected optimization algorithms, it is possible to determine the sensitive of the TCO and emission optimization by integrating BEVs into a company. Another advantage of the simulative interpretation: in simulated energy systems and vehicles, all parameters can be changed quickly, easily, and adapted to specific companies.

The basis of this virtual experiment is a detailed Matlab simulation which consists of individual sub-models. Another way of the usage of simulation models is shown by Unger et al. [29, 30], where the Modelica software is used for simulating a Green Building. The entire simulation model is shown in Fig. 3. Each sub-model has its own interfaces that define the inputs and outputs. The submodels are mainly linked by a mathematical vector with the time curve of $\mathrm{CO}_{2}$ emissions, energy, and power produced and consumed by the different systems.

\subsection{Sub-model: energy producer}

The first sub-model includes the simulation of different energy producers. Basically, there are different types of energy producers which can be integrated in commercial companies. These are:

- PV systems,

- Thermal power stations

- Wind turbines

- Biomass systems

- Geothermal systems

- Hydropower systems

- Fuel cells
However, only the PV system, the thermal power station, and the wind turbines are applicative to a company because of their mass availability, the advanced state of the art, and the easy integration to the company. To produce the first simulation results, this paper is focusing on the usage of a PV system. In the literature, there are many papers which display the simulation of a PV system in $[31,32]$. The simulation sequence in this paper is based on the work of Brendle [15] and is illustrated in Fig. 4.

The input for the PV simulation is a matrix with different weather parameters, which are obtained from an online database [33]. The website provides only historical weather data from different locations in Bavaria. For other areas and climate zones, another database has to be used. The focus in this approach is Southern Germany. In various sections, different sun parameters will be calculated. With these parameters, it is possible to calculate the global radiation $E_{\mathrm{G} \text {,gen }}$ on the inclined plane. With $E_{\mathrm{G}, \text { gen }}$, the energy and power produced by a PV system can now be simulated.

In this simulation, we are using the electrical equivalent circuit diagram of the two-diode model to describe the solar cell [34]. The solar cell model is parametrized with average values of different data sheets for a polycrystalline solar cell. In this simulation, it is possible to vary the area, the alignment (e.g., south-east), and the inclination of the $\mathrm{PV}$ plant to investigate influences on the energy production. By modifying these parameters, it is practicable to simulate almost any PV plant for individual companies.

\subsection{Sub-model: electric energy storage}

The second sub-model in the simulation is an electrical energy storage (EES), which consists of a battery pack of several individual battery cells. In this simulation, lithiumion cells are used. The task of the EES is to store the energy which is produced by the PV system as soon as it cannot be loaded directly into the BEV. The simulation of the EES shows how an additional stationary energy storage has an influence on the economy, private consumption, and the ecological balance of the company. The EES model consists of the following modules: [35]

- Equivalent circuit model: in this simulation, an equivalent circuit model of two RC elements is used. It describes the relationship between the output terminal voltage and the input variables: terminal current, state of charge (SOC), and the temperature of a cell. In this part, the current flow through the individual electrical components and also the voltage drop is calculated. The equivalent electrical parameters specified are not constant but depend on the state of charge, the battery ages, the current, and the temperature. 


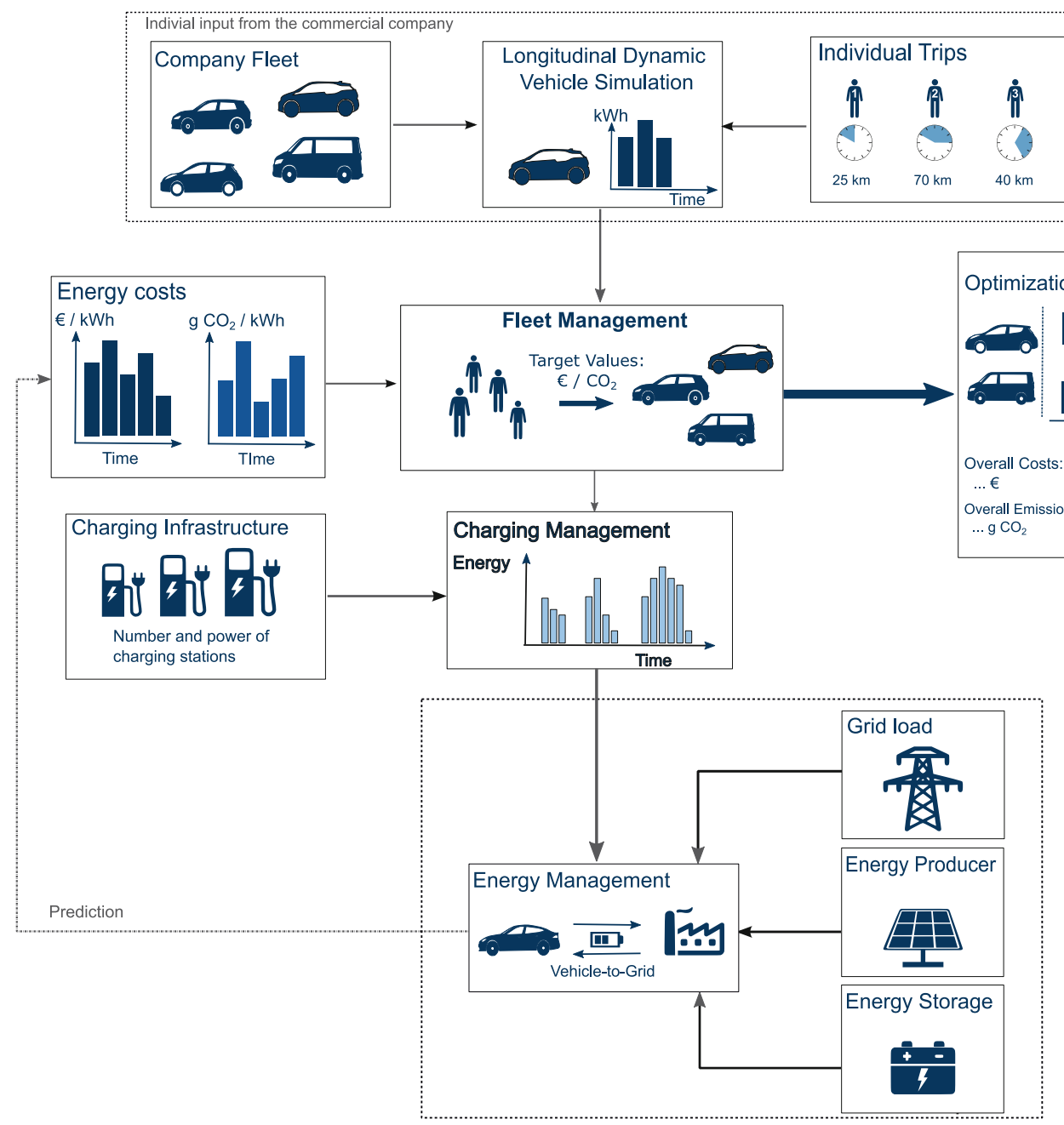

Fig. 3 Overall concept of the method development: virtual and real experiment

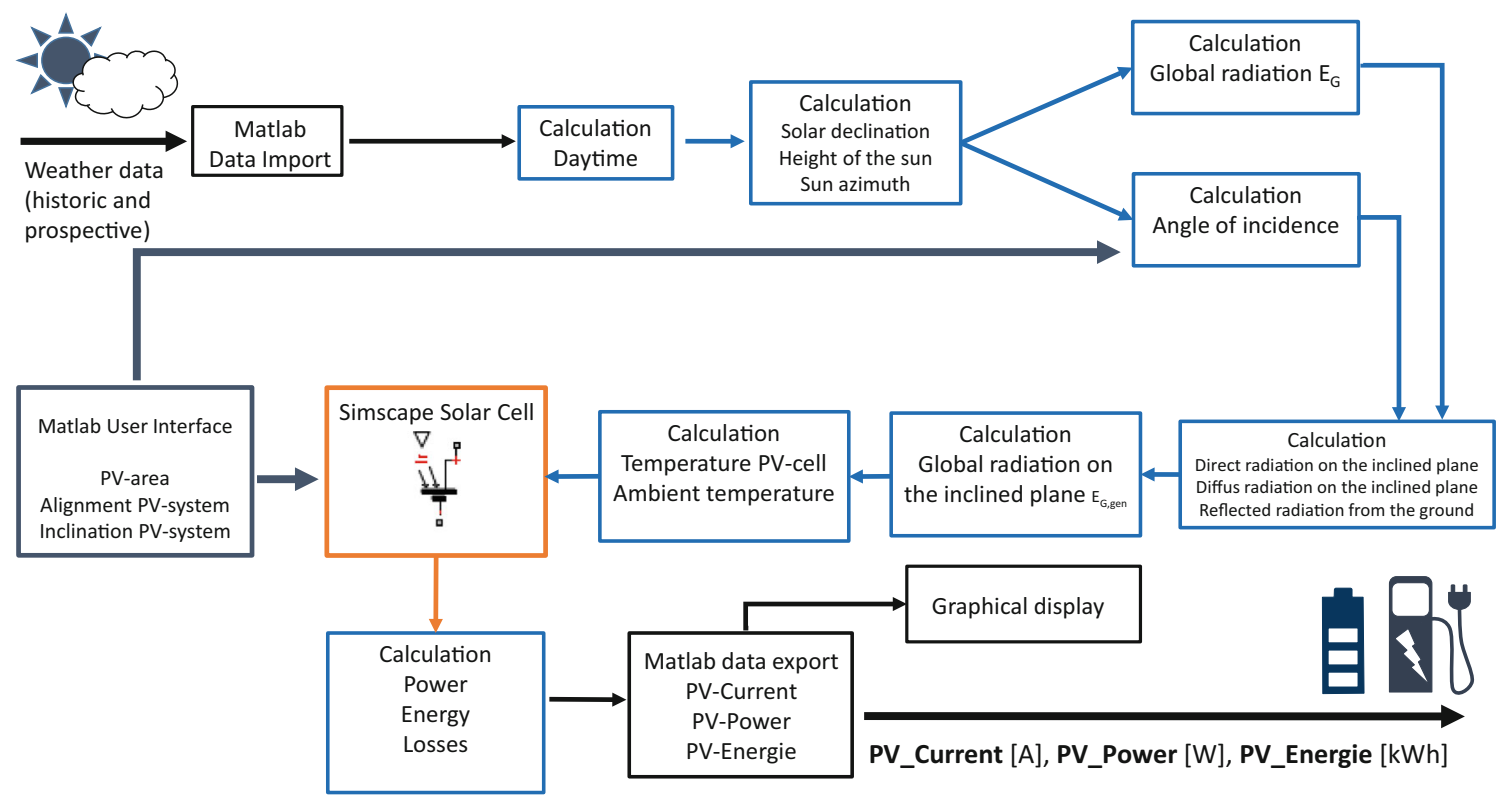

Fig. 4 Calculation process for the PV power and energy 
- Aging model: the aging mechanism describes the material change in a lithium cell, which is reflected in a decrease of the capacity and power reduction of the entire battery. Over the usage of several years, this effect is not negligible. When the cell is aging, an increase of the internal resistances and timers as well as a decrease of the capacity is visible. In the simulation, a factor is calculated which simulates the aging.

- SOC model: the charge state model describes the removable amount of charge from the battery under nominal conditions. In addition, a normalization to the nominal battery capacity occurs.

- Thermal model: since the temperature has a significant influence on the reaction rates of the primary and secondary reactions, the thermal consideration of a battery system is of central importance. To simplify a cell, it is assumed that the cell is homogeneous and that the temperature distributions can be neglected within a cell.

Therefore, the size of the battery capacity, the type of battery cells, and the initialization SOC can be varied. The output data of the simulation model are an SOC parameter, a state of health $(\mathrm{SOH})$ parameter, the battery energy, the efficiency, and the electrical voltage of the battery.

\subsection{Sub-model: charging infrastructure}

The third sub-model describes a Matlab model of the charging infrastructure. In this part, the user can predetermine the number of charging stations. Furthermore, the user has the choice between different maximum powers that can be provided from the charging station:

- Single-phase AC-loading: max. $3.7 \mathrm{~kW}$

- Three-phase AC-loading (16 A): $\max 11 \mathrm{~kW}$

- Three-phase AC-loading (32 A): $\max 22 \mathrm{~kW}$

- DC fast loading: $50 \mathrm{~kW}$

- Tesla supercharger: $120 \mathrm{~kW}$

On one hand, the focus in this sub-model is on the electrical implementation of the charging station. With electrical equivalent circuit diagrams, the basic power electronic components can be simulated and the losses in the charging station can be displayed. On the other hand, it is another objective to make the charging station smarter in contrast to the state-of-the-art charging stations. The charging station communicates with the charging-management systems and detects autonomously when and how much power it can transfer in the vehicle to reload the battery of the BEV.

\subsection{Sub-model: company fleet and vehicle simulation}

The last part of the simulation system is the longitudinal dynamic simulation of an electric vehicle. With real mobility data (velocity and acceleration profiles) of conventional vehicles, it is possible to simulate the energy consumption of various electric vehicles. Approaches for such a simulation are described in [37-39]. The simulation used in this paper is mostly based on the work of Jäger and Lienkamp [36]. The basic structure of the energy consumption is displayed in Fig. 5.

The input data are the basic parameters of the vehicle, such as length, width, height, or specific component data (motor power, capacity of the battery) and can be varied in the simulation. In addition, the signal of trips which were recorded by the GPS and acceleration sensors of a data logger is used as an input. This trip consists of a time position, acceleration, altitude, and velocity curve. With this input data, it is possible to calculate the energy consumption of a BEV in a longitudinal dynamics simulation. The powertrain is comprised of the electrical motor, inverter and gearbox, and the differential. To simplify the model, the battery is a constant voltage source.

\subsection{Sub-models: fleet-, energy-, and charging- management system}

It is the goal to integrate BEVs in commercial companies to reduce TCO and emissions in the company. To gain more advantages of the BEV usage, the authors suggest an intelligent combination of the BEVs with a fleet-, energy-, or charging-management system. In Fig. 4, the central system is the fleet or disposition system, which creates the TCO or emission optimized disposition plan for using the vehicles in the company. The idea in this paper is to use this disposition plan to create a charging plan for the charging-management systems. By writing this paper, different methods from the literature were considered as management systems for the usage in this approach.

An energy management system optimizes the operation of an energy system, based on production and demanded forecasts. Arboleya et al. presenting and efficient energy management approach in a Smart micro grid [40]. In [41, 42], the usage of renewable energy sources with electric vehicles is described. Further research results and models are displayed in [43-45].

The primarily goal of the energy management in these papers is an enlarged ratio of the self-consumption and thus the charging of electric vehicles by self-produced electricity. The EMS has to monitor the energy producers and energy consumers constantly to evaluate the energy 
Fig. 5 Basic structure of the energy flow model [36]

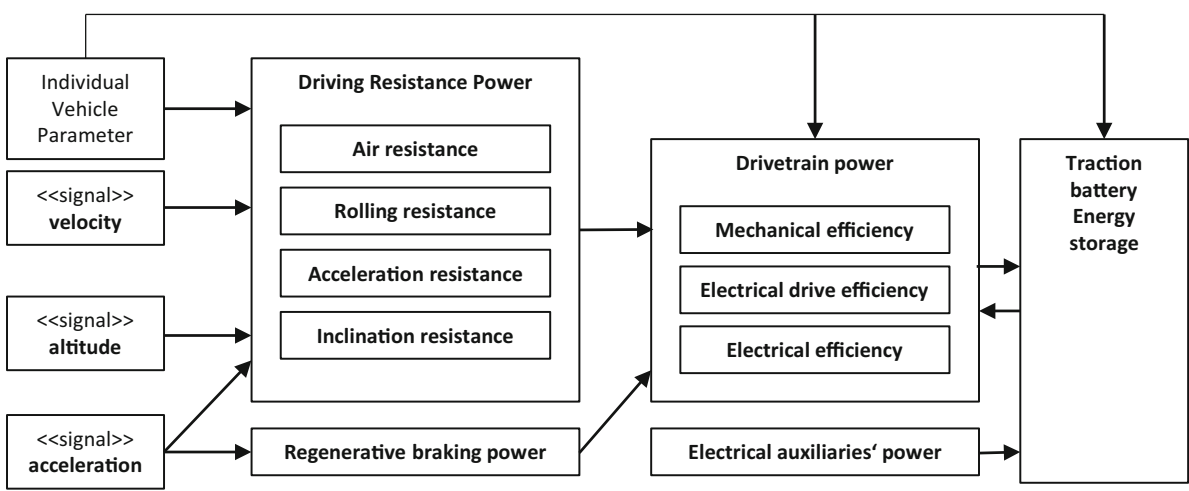

savings potential and the self-consumption optimization. Thereby, measures for increasing the self-consumption rate are generated, which means that the renewably generated energy is loaded directly into the vehicle or stored in the EES. To optimize the charging moments, first, a general approach for the charging stops has to be done [46-48]. After that, different methods for the optimal charging of a BEV have to be considered. Different papers, such as [49-51], describe algorithms and strategies for the optimized charging of an electric vehicle. For the integration of $\mathrm{BEVs}$, the charging of a whole electric fleet has to be considered, as it is described in [52-54].

The objective function (cost function), in which the optimization algorithm tries to minimize, is composed of the following parameters: energy from the grid, power supply, EES charge, EES discharge, EES state of charge, vehicle battery loading, vehicle battery state of charge. In addition, cost factors are used to weight the different parameters.

\section{Results and work in progress}

In this paper, we attempted to present an approach for developing a method for the integration of electric vehicles in commercial companies. Since the modeling of the individual simulation parts and management systems are still in progress, only a few results can presented. The exact modeling and the results of the fleet-management system are presented in [55].

The results of other projects and papers show that there is big potential to reduce the emissions and TCO by increasing the self-consumption rate of self-produced energy through the usage of BEVs in a private home. Since there is no work on developing a method for the integration of BEVs to commercial companies, the first simulation results of an energy management which includes a PV system, an energy storage, and different BEV vehicles in the company are presented.
Figure 6 displays the optimization for a day in the company. The selected PV system has an area of $100 \mathrm{~m}^{2}$ and is made of polycrystalline material. The EES has a capacity of $10 \mathrm{kWh}$, and the selected BEV vehicle was a BMW i3. In this case, the optimization was carried out for $1 \mathrm{~h}$ retroactively and it is assumed that the electric vehicle was available all day. For this simulation, a characteristic load profile was taken out of a company. The used optimization algorithm in this simulation was the Matlab given fmincon function, because the cost function is linear with additional linear and nonlinear boundary conditions. The cost function has the goal to optimize the usage of selfproduced energy using the EES or the electric vehicle.

The result of the simulation in Fig. 6 shows that the regenerative generated energy is first used for the compensation of the load in the company. As can be seen, the remaining energy between PV generated power and the base load of the company is loaded directly into the vehicle. Thus, with the energy management and the BEV vehicle, the self-consumption rate of regenerative produced energy in this company is increased from 61 to $100 \%$. If no vehicle was available or no energy management was integrated, the PV generated energy would by feedback in grid for less money. In this case, a profit of $13.08 €$ was gained using the self-produced energy. The EES is discharged in the morning and after that the grid load is increasing. The EES is not recharged again, because the

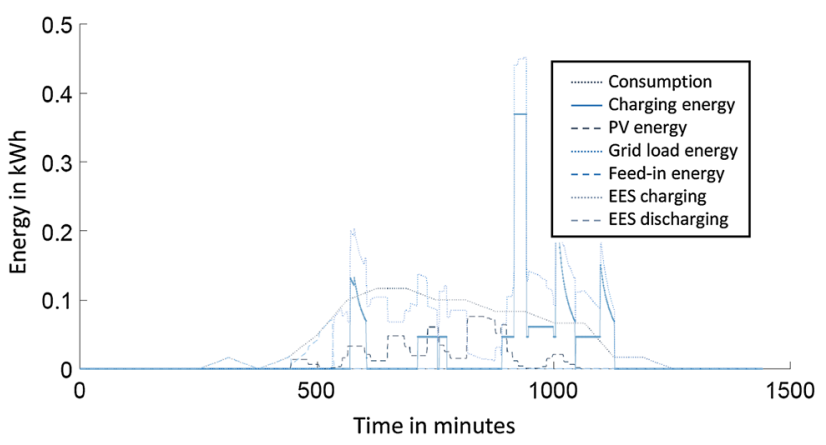

Fig. 6 Result of the energy management simulation 
consumption of the vehicle and the company exceed the production of the PV system.

Still there are many other variations of the simulation parameters, such as the addition of more BEV vehicles and the variation of the charging power. These first results show the basically integration of BEV vehicles in the company and confirm the results of the literature described in 4.4. In this case, it can be concluded that an energy management system in a commercial company using a $\mathrm{BEV}$ has a cost advantage. In addition, this management system can now be integrated in the fleet-management system described in [55] for more cost and emission advantages. Therefore, the simulation results in this paper have to be regarded as work in progress with more pending results.

\section{Summary}

In this paper, the authors present the approach for the development of a method for the integration of BEVs in commercial companies with a fleet-, energy-, or chargingmanagement system. The proposed approach is suited in a research project and combines a virtual and a real experiment. With collecting mobility and smart metering data in the real experiment, the simulation models in the virtual experiment can be evaluated and iterative developed.

The approach has the goal to develop a method for the integration of BEVs in commercial companies and to make validated decisions if and which management system has the most advantages for the company. These decisions are made by simulating the energy systems and the vehicle fleet of any company and described in the virtual experiment. By describing methods, analysis, and approaches from other research projects and papers, the authors want to give and overview of possible solutions for developing their own method and simulation system. In addition, the authors display with the related work the need of such an investigation, because there are no methods and simulation models which combine the described approach. Furthermore, the authors want to show with the preliminary results of an energy management system in this paper that with the integration of a BEV, it is possible to increase the selfconsumption of own produced renewable energy.

Acknowledgments We would like to thank the German Federal Ministry for Economic Affairs and Energy for funding the project VEM (Project VEM; 01MF12111). The work described in this paper was conducted with basic research fund of the Institute of Automotive Technology from the Technical University of Munich. Johannes Betz initiated the idea of the paper and contributed to development of the described method and the development of the simulation models. Markus Lienkamp contributed essentially to the conception of the research project. He revised the manuscript critically for important intellectual contend. He gave final approval of the version. As a guarantor, he accepts responsibility of the overall integrity of the manuscript.

\section{References}

1. Hacker, F., von Waldenfels, R., Mottschall, M.: Wirtschaftlichkeit von Elektromobilität in gewerblichen Anwendungen. ÖkoInstitut e.V, Berlin (2015)

2. Vogel, M.: Elektromobilität in gewerblichen Anwendungen. Begleit- und Wirkungsforschung Schaufenster Elektromobilität (BuW) (2015)

3. Trümper, S.C.: Commercial fleets as early markets for electric vehicles. In: proceedings of the IEEE 16th international conference on intelligent transportation systems (ITSC), pp. 1941-1946 (2013)

4. Frenzel, I., Jarass, J., Trommer, S., Lenz, B.: Erstnutzer von Elektrofahrzeugen in Deutschland. Deutsches Zentrum für Luftund Raumfahrt e. V. (DLR), Berlin (2015)

5. Aichinger, W.: Elektromobilität im städtischen Wirtschaftsverkehr. Deutsches Institut für Urbanistik GmbH, Berlin (2014)

6. Arnold, H., Kuhnert, F., Kurtz, R., Bauer, W.: Elektromobilität Herausforderungen für Industrie und öffentliche Hand. PricewaterhouseCoopers AG und Fraunhofer IAO, Frankfurt am Main (2010)

7. Vidačković, K., Weiner, N.: Anwenderstudie - Elektrofahrzeuge im Geschäftsumfeld. Fraunhofer IAO, Stuttgart (2013)

8. Gnann, T., Haag, M., Plötz, P., Wietschel, M.: Market potential for electric vehicles in the German commercial passenger transport sector. In: proceedings of the IEEE world electric vehicle symposium and exposition (EVS 27), pp. 1-10 (2013)

9. Lehrstuhl für Fahrzeugtechnik.: Virtuelle Elektromobilität für den Taxi und Handwerksverkehr München (VEM). https://www. ftm.mw.tum.de/de/forschungsfelder/smarte-mobilitaet/virtuelleelektromobilitaet-fuer-den-taxi-und-handwerksverkehr-muenchen/ (2012). Accessed 21 Jun 2015

10. de Cauwer, C., Gillis, D., Coosemans, T., van Mierlo, J.: Identification of EV use patterns, based on large scale EV monitoring data. In: proceedings of the IEEE world electric vehicle symposium and exposition (EVS 27), pp. 1-11 (2013)

11. Gong, Q., Midlam-Mohler, S., Marano, V., Rizzoni, G., Guezennec, Y.: Statistical analysis of PHEV fleet data. In: proceedings of the IEEE vehicle power and propulsion conference, pp. 1-6 (2010)

12. Meyer, T., Pfriem, M., Gauterin, F.: Selected results from a largescale field operational test with electric vehicles in Germany and France. In: proceedings of the IEEE 5th IET hybrid and electric vehicles conference (HEVC 2014), pp. 1-7 (2015)

13. Pearre, N.S., Kempton, W., Guensler, R.L., Elango, V.V.: Electric vehicles: how much range is required for a day's driving? Transp Res Part C: Emerg Technol 19(6), 1171-1184 (2011)

14. Schwan, T., Unger, R., Bäker, B.: Modelling and optimization or renewable energy supply for electrified vehicle fleet. In: proceedings of the 8th conference on sustainable development of energy, water and environment systems (2013)

15. Brendle, B., Hamacher, T., Lienkamp, M., Wilhelm, C., Papajewski, J., Gebhard, P., Riedel, A., Benda, V.: Model-Predictive energy management for the integration of plug-in-hybrid electric vehicles into building energy systems. In: proceedings of the SAE SAE 2013 world congress and exhibition (2013)

16. Link, J.: Elektromobilität und erneuerbare Energien: Lokal optimierter Einsatz von netzgekoppelten Fahrzeugen. Dissertation, Fakultät für Elektrotechnik und Informationstechnik, Technische Universität Dortmund, Dortmund (2011) 
17. Mierau, M., Noeren, D., Becker, F.: Potential der Ladung von Elektrofahrzeugen durch Photovoltaikenergie im Privathaushalt, Freibaur (2014)

18. Maasmann, J., Bocker, S., Rettberg, F., Wietfeld, C., Rehtanz, C.: Renewable energies in smart factories with electric vehicle fleets. In: proceedings of the IEEE 49th international universities power engineering conference (UPEC), pp. 1-6 (2014)

19. Valero-Bover, D., Olivella-Rosell, P., Villafafila-Robles, R., Cestau-Cubero, S.: Performance analysis of an electric vehicle fleet for commercial purposes. In: proceedings of the IEEE international electric vehicle conference (IEVC), pp. 1-6 (2014)

20. Taefi, T., Fink, A., Kreutzfeldt, J., Held., T.: A framework to enhance the productivity of electric commercial vehicles in urban freight transport (2013)

21. Samweber, F., Nobis, P., Gallet, M.: Den eigenen PV-Strom tanken: Ladesteuerung zur Erhöhung des Photovoltaik-Eigenverbrauchs (Teil 2). BWK 66, 46-49 (2014)

22. Quaschning, V., Weniger, J., Tjaden, T.: Chancen des photovoltaischen Eigenverbrauchs für die Energiewende in Deutschland (2014)

23. Kahlen, M., Valogianni, K., Ketter, W., van Dalen, J.: A profitable business model for electric vehicle fleet owners. In: proceedings of the IEEE international conference on smart grid technology, economics and policies (SG-TEP), pp. 1-5 (2012)

24. Allgäuer Überlandwerk GmbH.: IRENE.: Integration regenerativer Energien und Elektromobilität. http://www.projekt-irene.de/ index.html (2015). Accessed 21 Jun 2015

25. Planungsbüro Koenzen.: lokSMART.: Lokale smart grids. http:// www.loksmart.de/ (2015). Accessed 31 Jul 2015

26. Das Fraunhofer-Institut für Arbeitswirtschaft und Organisation IAO.: Shared e-Fleet. http://www.shared-e-fleet.de/index.php/de (2015). Accessed 21 Jul 2015

27. Sassi, O., Oulamara, A.: Lecture notes in computer science, computational science and its applications-ICCSA 2014. In: Hutchison, D. (ed.) Joint scheduling and optimal charging of electric vehicles problem, pp. 76-91. Springer International Publishing, Cham (2014)

28. Döppers, F.-A., Iwanowski, S.: E-mobility fleet management using ant algorithms. Procedia Soc Behav Sci 54, 1058-1067 (2012)

29. Unger, R., Schwan, T., Mikoleit, B., Bäker, B., Kehrer, C., Rodemann, T.: Green building-modelling renewable building energy systems and electric mobility concepts using Modelica. (2012)

30. Unger, R., Schwan, T.: Energie-Efficient desing of a research greenhouse. Presented at the 18th ITI Symposium, Dresden (2015)

31. Bellia, H., Youcef, R., Fatima, M.: A detailed modeling of photovoltaic module using MATLAB. NRIAG J Astron Geophys 3(1), 53-61 (2014)

32. Belhaouas, N., Ait Cheikh, M.S., Malek, A., Larbes, C.: MatlabSimulink of photovoltaic system based on a two-diode model simulator with shaded solar cells. Revue des Energies Renouv 16, 65-73 (2013)

33. Bayerische Landesanstalt für Landwirtschaft.: Agrarmeterologie Bayern. www.wetter-by.de/ (2015). Accessed 21 Jun 2015

34. TheMathWorks.: Solar cell. http://de.mathworks.com/help/phys $\mathrm{mod} / \mathrm{elec} / \mathrm{ref} / \mathrm{solarcell.html}$ ?refresh=true (2015). Accessed $21 \mathrm{Jun}$ 2015

35. Jossen, A., Späth, V.: Simulation von Batteriesystemen. http:// www.basytec.de/simulation/Batmodell.html (2015). Accessed 21 Jun 2015

36. Jäger, B., Lienkamp, M.: Smartphone-based energy consumption simulation for electric vehicles. Presented at the conference on future automotive-COFAT 2014. München (2014)
37. Gao, D.W., Mi, C., Emadi, A.: Modeling and simulation of electric and hybrid vehicles. Proc. IEEE 95(4), 729-745 (2007)

38. da Fonte Terras, J.M., Neves, A., Sousa, D.M., Roque, A.: Modelling and simulation of a commercial electric vehicle. In: Proceedings of the IEEE 13th International Conference on Intelligent Transportation Systems (ITSC), pp. 1588-1593 (2010)

39. Butler, K.L., Ehsani, M., Kamath, P.: A Matlab-based modeling and simulation package for electric and hybrid electric vehicle design. IEEE Trans. Veh. Technol. 48(6), 1770-1778 (1999)

40. Arboleya, P., Gonzalez-Moran, C., Coto, M., Falvo, M.C., Martirano, L., Sbordone, D., Bertini, I., Di Pietra, B.: Efficient energy management in smart micro-grids: ZERO grid impact buildings. IEEE Trans Smart Grid 6(2), 1055-1063 (2015)

41. Panwar, L.K., Reddy, K.S., Kumar, R.: Productive use of distributed renewable generation source with electric vehicle in smart grid. In: proceedings of the IEEE 6th power India international conference (PIICON), pp. 1-6 (2014)

42. Le Goff Latimier, R., Kovaltchouk, T., Ben Ahmed, H., Multon, B.: Preliminary sizing of a collaborative system: Photovoltaic power plant and electric vehicle fleet. In: proceedings of the IEEE ninth international conference on ecological vehicles and renewable energies (EVER), pp. 1-9 (2014)

43. Lutzenberger, M., Kuster, T., Albayrak, S.: Integrating electric vehicles into smart grid infrastructures a simulation-based approach that became reality. In: proceedings of the IEEE winter simulation conference (WSC), pp. 1061-1072 (2014)

44. Ottensmann, A., Haubrock, J., Westermann, D.: Forecast of the aggregated charging power of electric vehicles in commercial fleets. In: proceedings of the IEEE international electric vehicle conference (IEVC), pp. 1-5 (2014)

45. Stifter, M., Ubermasser, S.: Dynamic simulation of power system interaction with large electric vehicle fleet activities. In: proceedings of the IEEE Grenoble PowerTech (POWERTECH), pp. 1-6 (2013)

46. Alesiani, F., Maslekar, N.: Optimization of charging stops for fleet of electric vehicles: a genetic approach. IEEE Intell Trans Syst Mag 6(3), 10-21 (2014)

47. Gacias, B., Meunier, F.: Locating charging points for an electric fleet. Presented at the 9th international conference of modeling, optimization and simulation. Bordeaux (2012)

48. Deng, B., Wang, Z.: Research on electric-vehicle charging station technologies based on smart grid. In: proceedings of the IEEE Asia-Pacific power and energy engineering conference (APPEEC 2011), pp. 1-4 (2011)

49. Chen, N., Tan, C.W., Quek, T.Q.S.: Electric vehicle charging in smart grid: optimality and valley-filling algorithms. IEEE J Sel Top Signal Process 8(6), 1073-1083 (2014)

50. Gonzalez, L., Novella, H., Gutierrez, E., Ventura, J., Mogas, P.: EVIC (electric vehicle intelligent charging). In: proceedings of the IEEE world electric vehicle symposium and exposition (EVS 27), pp. 1-8 (2013)

51. Mets, K., Verschueren, T., Haerick, W., Develder, C., de Turck, F.: Optimizing smart energy control strategies for plug-in hybrid electric vehicle charging. In: proceedings of the IEEE IFIP network operations and management symposium workshops, pp. 293-299 (2010)

52. Hu, J., Ostergaard, J., Lind, M., Wu, Q.: Optimal charging schedule of an electric vehicle fleet. In: proceedings of the IEEE 46th international universities' power engineering conference (UPEC), pp. 1-6 (2011)

53. Plota, E., Rehtanz, C.: Impact of controlled charging of an electrical vehicle fleet on business efficiency. In: proceedings of the IEEE 49th international universities power engineering conference (UPEC), pp. 1-6 (2014) 
54. Parker, T., Naberezhnykh, D.: Charging point strategies for electric commercial vehicles. In: proceedings of the IEEE hybrid and electric vehicles conference (HEVC 2013), pp. 1-4 (2014)

55. Betz, J., Werner, D., Lienkamp, M.: Fleet disposition modeling to maximize utilization of battery electric vehicles in companies with on-site energy generation. Presented at the international scientific conference on mobility and transport transforming urban mobility_mobil.TUM. München (2016) 